\title{
“O QUE A PSICANÁLISE PODE ENSINAR SOBRE A CRIANÇA, SUJEITO EM CONSTITUIÇÃO" ENTREVISTA COM A PROFESSORA LEDA MARIZA FISCHER BERNARDINO
}

\author{
"What Psychoanalysis Can Teach About Children, \\ The Human Being In Development" \\ Teacher Leda Mariza Ficher Bernardino, In Interview
}

Por Sirlene Guimarães ${ }^{1}$

A professora Leda Mariza Fischer Bernardino é professora titular do curso de Psicologia da PUCPR, Especialista em Disfunções Neuropsicossociais e o Processo Ensino Aprendizagem (PUCPR), Mestre em Psicologia Clínica e Psicopatologia pela Université Paul Valéry (França) e Doutora em Psicologia Escolar e do Desenvolvimento Humano pela USP. É psicanalista, membro fundador da Associação Psicanalítica de Curitiba, analista membro da Association Lacanienne Internationale e membro da Associação Universitária de Pesquisa em Psicopatologia Fundamental. Publicou como organizadora os livros "Neurose infantil versus neurose da criança" (Editora Àgalma, 1997), "O bebê e a modernidade: abordagens teóricoclínicas” (Ed. Casa do Psicólogo, 2002), “Psicanalisar crianças: que desejo é esse?” (Ed. Ágalma, 2004) e é autora do livro "As psicoses não decididas da infância: um estudo psicanalítico” (Ed. Casa do Psicólogo, 2004).

Em outubro passado, a professora Leda Bernardino lançou em São Paulo o novo livro que organizou, pela Editora Escuta, "O que a psicanálise pode ensinar sobre a criança, sujeito em constituição", sobre o qual falará conosco nesta entrevista.

Pergunta: Qual o tema deste novo livro que você acaba de lançar?

Resposta: O livro é o resultado de um trabalho iniciado em 1999, com a minha participação na Pesquisa Multicêntrica de Indicadores Clínicos para o Desenvolvimento Infantil, na qual atuo como coordenadora em Curitiba e como coordenadora da região sul. Nesta pesquisa, realizada em dez centros brasileiros, desenvolvemos um protocolo de indicadores de risco psíquico a ser aplicado por pediatras nas consultas de rotina dos primeiros 18 meses de vida, no serviço público. Ao trabalhar com a capacitação dos

1 Aluna do 8. Período do Curso de Psicologia PUCPR e Bolsista da Revista Psicologia Argumento. Endereço: R. José Miranda de Castro n. $\underline{0}$ 73, Bairro Portão, Curitiba-PR, CEP: 80.330-280. E-mail:sirlene55@yahoo.com.br. 
pediatras que atuaram na pesquisa, foi necessánio transpor para uma linguagem simples uma série de conceitos psicanalíticos sobre o processo de constituição psíquica de um sujeito. O capítulo que escrevi e que abre o livro é justamente resultado deste esforço de transmissão de conceitos para um público não psi, que trabalha clinicamente com crianças, a partir de minha experiência de interlocução com este grupo de pediatras. Além dos pediatras, participaram da pesquisa aqui em Curitiba quatro monitoras psicanalistas, que acompanharam os pediatras na aplicação inicial do protocolo, na fase de treinamento. Periodicamente, nossa equipe de psicanalistas se reunia para discutir questões teónicas decorrentes desta expeniência de pesquisa. Destas reuniões resultaram os demais artigos da pnimeira parte do volume, de Rosa Mariotto (também professora da PUCPR), Rosane Licht, Melania Medeiros e Jaqueline Sanson, que abordam questões como estrutura, desenvolvimento, pesquisas neurológicas sobre psicopatologias, o trabalho com os pediatras e as mães durante as consultas.

Pergunta: O livro aborda o trabalho de outros grupos nacionais que trabalham nesta pesquisa?

Resposta: Na verdade, o livro dá início a uma coleção intitulada "Psicanálise e infância", dirigida pela coordenadora nacional da pesquisa, a professora livre-docente Maria Cristina Machado Kupfer, do Instituto de Psicologia da USP. O trabalho do grupo de Curitiba está neste primeiro volume. A idéia é que nos próximos volumes sejam contemplados os trabalhos de outros grupos, como o de Recife, por exemplo, que provavelmente estará no segundo volume. Por outro lado, na segunda parte deste volume que organizei, estão artigos apresentados em Paris, por colegas psicanalistas que também trabalham com pesquisas com bebês, no Colóquio Universitário FrancoBrasileiro sobre Clínica com Bebês: o suporte da pesquisa, que ocorreu em janeiro de 2005, na Université de Paris VII, no qual também apresentamos nossa pesquisa. Temos artigos de Marie Christine Laznik, pesquisadora do grupo PréAut - Prevenção do Autismo, de Claude Boukobza, do Centro de Acolhimento Mães-Bebês de Saint Denis e de Marie Claude Fourment-Aptekman, da Université de Paris XIII. Para concluir o volume, temos um artigo de Christian Dunker, psicanalista e professor do Instituto de Psicologia da USP, responsável pelo texto mais denso do volume, propondo uma discussão sobre a questão da estrutura e da constituição do sujeito na obra de Lacan.
Pergunta: O livro é acessível aos estudantes?

Resposta: Penso que sim, pois faz parte do espínito desta coleção "Psicanálise e infância" tomar mais acessíveis, para um público mais amplo, os conceitos psicanalíticos so bre a criança, sobre temas como constituição do sujeito, pulsão, operações psíquicas, transferência e outros. Presta-se, portanto, a uma interlocução não só com os estudantes de psicologia, mas de outras áreas clínicas, como medicina, fonoaudiologia, fisioterapia, e mesmo para os estudantes de pedagogia, assim como com profissionais destas áreas, que atuam com crianças e se beneficiam muito com o conhecimento dos aspectos psíquicos do desenvolvimento infantil e de aspectos presentes em toda clínica, como a transferência. finalizada?

Pergunta: Esta pesquisa multicêntrica já foi

Resposta: Aqui em Curitiba, sim. Como se trata de um estudo transversal e longitudinal, a primeira fase - de aplicação dos protocolos pelos pediatras -, foi finalizada no final de 2004. A segunda fase - de avaliação psicanalítica e psiquiátrica de uma subamostra das crianças - realizada no momento em que completam 3 anos, finalizou no mês de setembro passado. Mas ainda há outros centros que não finalizaram esta segunda etapa. A previsão é de que em agosto de 2007 teremos condições de apresentar os resultados da pesquisa no âmbito nacional, ou seja, quais indicadores de risco psíquicos foram validados, que serão então incluídos na ficha de desenvolvimento do Ministério da Saúde, órgão que encomendou esta pesquisa.

Pergunta: Como você avaliaria esta expeniência de pesquisa da qual participou e que resultou neste livro?

Resposta: Avalio como muito positiva, pois me permitiu compartilhar discussões teónicas muito ricas, com colegas psicanalistas de vánias partes do Brasil e pertencentes a instituições bem diversas. Possibilitou o contato com os pediatras da Unidade de Saúde da Criança da Prefeitura de Curitiba, profissionais com uma prática clínica muito vasta e interessante. Ensejou a oportunidade de realizar uma pesquisa de amplo porte e de tanta importância para a prevenção em saúde mental, um de meus objetivos enquanto professora universitánia é se possível vislumbrar conseqüências para a minha clínica e de outros colegas que trabalham com crianças com problemas graves de desenvolvimento, como a possibilidade de receber encaminhamentos para tratamento mais precocemente, o que em termos de prognóstico é muito favorável. 